\title{
Honorary Foreign Members of the Scientific Council on Analytical Chemistry
}

\section{DOI: $10.1134 / \mathrm{S} 1061934809070016$}

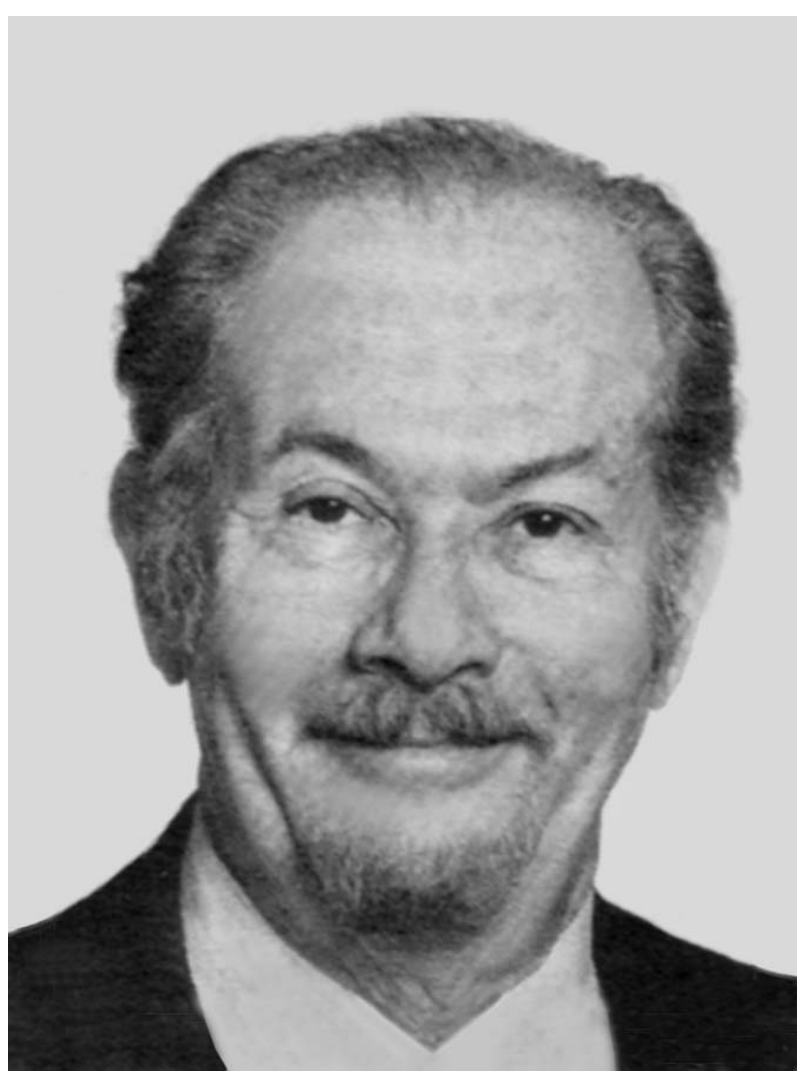

Photo 1. Professor Henry Fraiser.

In the beginning of the 1990s, the Scientific Council on Analytical Chemistry of the Academy of Sciences of the USSR founded the Institute of Honorary Foreign Members. At that time, Professor Henry Freiser (United States, Photo. 1) and Professor Taitiro Fujinaga (Japan, Photo. 2) were elected as Honorary Foreign Members of the Council.

Henry Frajzer, Emeritus Professor of the University of Arizona (Tucson) is a well-known American analyst, a scientist, a teacher, and an author of 12 monographs and 400 scientific papers and patents. His works are devoted to liquid-liquid extraction, ion-selective electrodes, and equilibria in solutions. He was born in the United States in 1920, obtained the Doctor of Philosophy degree in 1944 at Duke University, and started

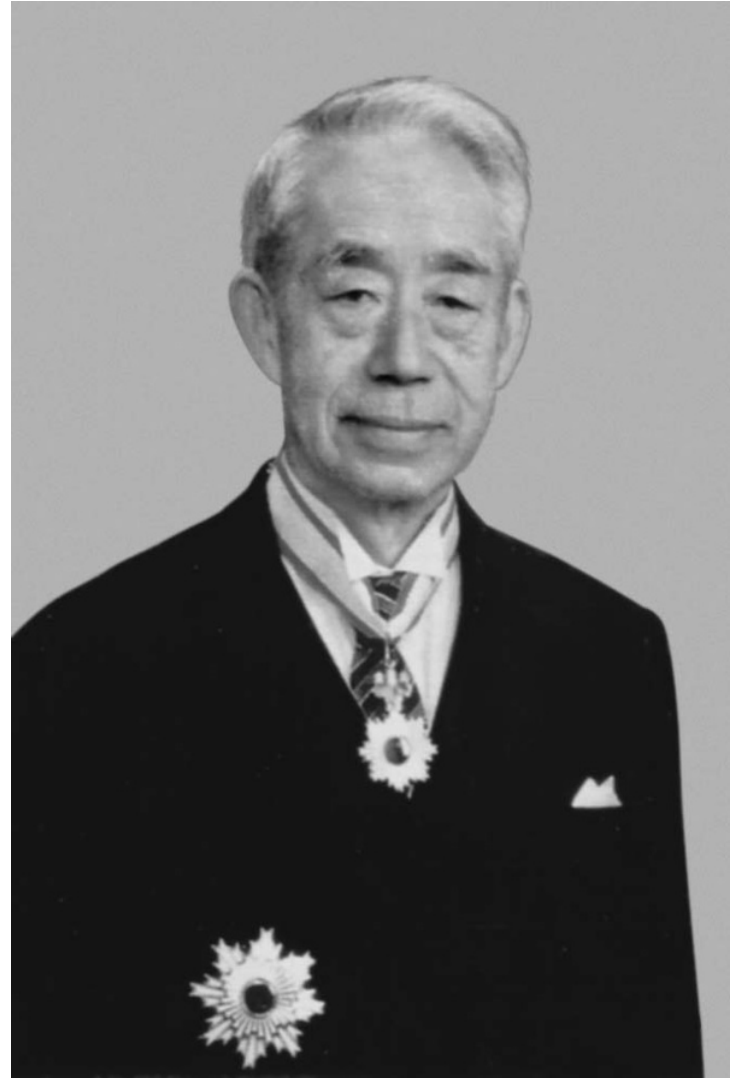

Photo 2. Professor Taitiro Fujinaga.

working in Arizona from the 1950s. Professor Freiser is the author of the first book on extraction in its applications to analytical chemistry; he has also conducted research into extraction kinetics. Professor Freiser is the discoverer of coated-wire ion-selective electrodes. In 1978, he received an award of the American Chemical Society (ACS); in 1986, the Anachem Award; in 1990, the ACS Award in Separation Science and Technology; and in 1996, the Carl Hanssen Medal of the International Committee on Solvent Extraction. Many times, starting from, 1965 he visited the USSR and took part in Soviet (Russian)-Japanese Symposia on Analytical Chemistry. In 2010, Henry Freiser will turn ninety.

Taitiro Fujinaga for long years has been the Professor of Analytical Chemistry of the Kyoto University. 
His works are devoted mainly to electrochemical methods of analysis, and he is a well-known expert in this field. One of the founders of the Osaka Institute of Ocean Chemistry. Professor Fujinaga is one of the organizers of the Soviet (Russian)-Japanese Symposium on Analytical Chemistry, which has been held regularly for almost twenty years. He has visited Russia several times. In January 2009, Professor Taitiro Fujinaga celebrated his 90th birthday.
In 2007, the Bureau of the Scientific Council on Analytical Chemistry of the Russian Academy of Sciences approved the Statutes of Honorary Foreign Members of the Council. It was published in the Zhurnal Analiticheskoi Khimii in the same year.

Yu. A. Zolotov 